\title{
АКТУАЛЬНЫЕ ПРОБЛЕМЫ ПРОВЕДЕНИЯ СУДЕБНОЙ СТРОИТЕЛЬНО-ТЕХНИЧЕСКОЙ ЭКСПЕРТИЗЫ В ПРОЦЕССЕ РАССЛЕДОВАНИЯ ПРЕСТУПЛЕНИЙ, СВЯЗАННЫХ С ХИЩЕНИЯМИ ПРИ СТРОИТЕЛЬСТВЕ ЗДАНИЙ И СООРУЖЕНИЙ
}

\section{CURRENT PROBLEMS OF CONDUCTING FORENSIC CONSTRUCTION \\ AND TECHNICAL EXAMINATIONS \\ ING CRIMES RELATED TO THEFT IN THE CONSTRUCTION OF BUILDINGS AND FACILITIES}

D. Sokolova

D. Brager

I. Litvinov

Summary: In this article, based on the analysis of literary sources and the practice of conducting a judicial construction and technical expertise in the process of investigating crimes related to theft in the construction of buildings and structures, the actual problems of its purpose and production are revealed. The author outlines the stages of production and the appointment of a forensic construction and technical examination, reveals the features of a full-scale inspection of the scene. It is emphasized that a possible way out of this situation can be the interaction of the person who appointed the examination with the expert who is entrusted with its production at all stages of its conduct, as well as providing him with all possible assistance, which will ensure objectivity, comprehensiveness and completeness of the research results. Proposals are being made aimed at improving the procedure for the appointment and production of judicial construction and technical expertise.

Keywords: forensics, detection and investigation of crimes, methods of investigation of crimes related to theft during the construction of buildings and structures, special knowledge, forensic construction and technical expertise, field inspection.
Соколова Дарья Дмитриевна

Дальневосточный государственный университет

путей сообщения,

2. Хабаровск

Брагер Дмитрий Константинович

К.ю.н., дочент, Сахалинский институт железнодорожного транспорта - филиал «Дальневосточный государственный университет путей сообщения»

в г. Южно-Сахалинске, brager-4@mail.ru

Литвинов Иван Иванович

директор, Сахалинский институт железнодорожного транспорта - филиал «Дальневосточный государственный университет путей сообщения»

в г. Южно-Сахалинске

Аннотация: В настоящей статье на основе анализа литературных источников и практики проведения судебной строительно-технической экспертизы в процессе расследования преступлений, связанных с хищениями при строительстве зданий и сооружений, раскрываются актуальные проблемы ее назначения и производства. Автором обозначены этапы производства и назначения судебной строительно-технической экспертизы, раскрыты особенности проведения натурного осмотра места происшествия. Подчеркивается, что возможным выходом из сложившейся ситуации может служить взаимодействие лица, назначившего экспертизу с экспертом, которому поручено его производство на всех этапах ее проведения, а также оказание ему всемерной помощи, что позволит обеспечить объективность, всесторонность и полноту результатов исследования. Вносятся предложения, направленные на совершенствование процедуры назначения и производства судебной строительно-технической экспертизы.

Ключевые слова: криминалистика, раскрытие и расследование преступлений, методика расследования преступлений, связанных с хищениями при строительстве зданий и сооружений, специальные познания, судебная строительно-техническая экспертиза, натурный осмотр.

Отдельные аспекты производства судебной строительно-технической экспертизы при раскрытии преступлений, связанных с хищениями в сфере строительства зданий и сооружении исследовались: А.Ю. Бутыриным, И.В. Веренич, А.К. Орловым, Н.С. Савенковой, А.Е. Фоменко и др. [1, 2-6].

Производство судебной строительно-технической экспертизы обусловлено необходимостью установления криминалистически значимой информации для раскрытия и расследования хищений в сфере строительства, в 
случаях, когда знаний лиц, в производстве которых находится уголовное дело недостаточно.

Для обеспечения всесторонности исследования при производстве судебной строительно-технической экспертизы требуется проведение осмотров объектов недвижимости и функционально связанных с ними территорий. Поскольку в качестве объектов экспертизы выступают объекты недвижимости, которые по своей природе немобильны, возникает необходимость проведения натурного осмотра на месте расположения объекта [3, с. 413].

Производство судебной строительно-технической экспертизы состоит из трех этапов: подготовительного, предварительного (визуального) исследования и детального (инструментального) исследования.

Подготовительный этап заключается в предварительном консультировании, систематизации представленных на экспертизу документов, назначении даты и времени проведения натурного осмотра, а также организации выезда на осмотр. Эксперт уже в рамках подготовительного этапа сталкивается с некомпетентностью следователей, назначающих экспертизу, выражающейся в некорректной постановке вопросов, содержащихся в постановлении о назначении экспертизы.

Типичными примерами некорректности вопросов, служат: дублирование вопросов, имеющих единый смысл, но разную формулировку; постановка вопросов, не имеющих отношения к задачам судебной строительно-технической экспертизы; постановка вопросов, носящих ревизионный характер [4, с. 98].

В числе факторов, обусловливающих эффективность экспертного исследования, важная роль отводится конкретности поставленной задачи, полноте и качеству представленных на экспертизу исходных сведений и материалов, а также корректности поставленных перед экспертом вопросов.

Представляется, что выходом из сложившейся ситуации может служить проведение обучающих семинаров и обязательное предварительное консультирование следователей по вопросам, касающимся назначения и производства судебной строительно-технической экспертизы.

В целях формирования эффективного юридического механизма реализации обозначенного предложения считаем целесообразным закрепить на законодательном уровне правовую норму, регламентирующую проведение предварительных консультаций следователей перед назначением экспертизы, дополнив главу 27 Уголовно-процессуального кодекса Российской Федерации (далее - УПК РФ) статьей 195.1 «Предварительное консультирование эксперта», изложив ее в следующей редакции:

1. «Перед назначением экспертизы следователь обращается в экспертное учреждение за консультацией экспертов, обладающих специальными знаниями в соответствующей области.

2. В ходе консультации эксперт разъясняет следователю содержание предмета, объектов и задач предстоящей экспертизы, а также раскрывает перечень вопросов, которые могут быть поставлены перед экспертом».

Второй проблемой, возникающей на подготовительном этапе судебной строительно-технической экспертизы, является представление недостаточного объема необходимых материалов для полноты экспертного исследования и формирования сроков ее производства.

Для решения обозначенной проблемы представляется необходимым закрепить в предлагаемой редакции статьи 195.1 «Предварительное консультирование эксперта» ч. 3 и ч. 4, изложив их в следующей редакции:

3. «В необходимых случаях на консультацию может быть приглашен специалист, которого следователь планирует привлечь для получения необходимых для производства экспертизы криминалистических образцов.

4. В ходе проведения консультации эксперт разъясняет следователю и специалисту существующие методики получения криминалистических объектов, а также требования, предъявляемые к их количеству и качеству».

Полагаем, что обозначенные предложения могут способствовать совершенствованию процедуры назначения судебных экспертиз в целом, а не только судебной строительно-технической экспертизы.

На этапе предварительного (визуального) обследования также нередко возникают проблемы:

1. Установление новых фактов относительно исследуемого объекта. Для решения обозначенной проблемы представляется необходимым, чтобы следователи оказывали всемерное содействие эксперту, которому поручено производство экспертизы в получении новой дополнительной информации относительно объекта экспертного исследования.

Полагаем, что механизм содействия эксперту со стороны следователя в процессе производства экспертизы должен быть закреплен на законодательном уровне. С этой целью, считаем необходимым дополнить статью 199 УПК РФ «Порядок направления материалов уголовного дела для производства судебной экспертизы» ча- 
стью 6, изложив ее в следующей редакции:

5. «В случае установления новых фактов, имеющих отношение к исследуемому объекту, эксперт, которому поручено производство экспертизы, вправе обратиться к следователю за предоставлением необходимой дополнительной информации. Следователь обязан предоставить эксперту запрашиваемую информацию в разумные сроки».

2. Удаленность объекта, подлежащего экспертному исследованию. Решением обозначенной проблемы выступает использование в качестве доказательства, протокола осмотра места происшествия, а равно данных, полученных посредством применения современных измерительных приборов - квадрокоптера, камеры на 360 градусов для проведения натурных осмотров.

Для решения обозначенной проблемы считаем необходимым оснащать каждое экспертное учреждение, в котором производятся судебные строительно-технические экспертизы современной техникой, измерительными приборами и фото-, видеоаппаратурой.

Кроме того, считаем целесообразным ежегодно проводить в экспертных учреждениях курсы повышения квалификации, круглые столы и семинары с приглашением ведущих специалистов в области применения современной экспертно-криминалистической техники, использование которой открывает новые возможности судебной строительно-технической экспертизы и способствует повышению качества ее производства, а также использования полученных результатов в раскрытии и расследовании преступлений в строительной сфере.

Анализ практики производства судебных строительно-технических экспертиз в рамках уголовного судопроизводства позволил прийти к выводу, что в качестве материалов, представляемых для производства выступают альбомы чертежей, в которых отражаются архитектурно-планировочные решения, исследуемого объекта, поэтажные планы, общие эскизные материалы. Однако представляемых материалов, недостаточно для производства всестороннего и полного производства и формирования исчерпывающих ответов на поставленные вопросы. При производстве натурного осмотра эксперты стремятся восполнить недостающие сведения.

При этом не всегда сведений, полученных при производстве натурных осмотров достаточно для производства всестороннего и полного экспертного исследования. В подобных случаях, эксперты ходатайствуют перед лицом, назначившим экспертизу, о предоставлении недостающих сведений. Ходатайство может быть удовлетворено в течение двадцати дней. Поскольку до момента удовлетворения ходатайства производство экспертизы приостанавливается, срок ее производства затягивается.
Полагаем, что внесенное ранее предложение о дополнении статьи 199 УПК РФ частью 6 будет способствовать решению обозначенной проблемы.

Кроме того, у эксперта возникает проблема, обусловленная тем, что представленные документы, как правило, поступают в разрозненном виде (не прошиты и не скреплены печатью), не имеют сквозной нумерации, что существенно осложняет процесс обработки исходных материалов для проведения исследования.

Для решения обозначенной проблемы, представляется необходимым дополнить статью 199 «Порядок направления материалов уголовного дела для производства судебной экспертизы» частью 1.1., изложив ее в следующей редакции:

«1.1. Материалы, необходимые для производства судебной экспертизы должны быть систематизированы, прошиты, пронумерованы и содержать опись».

После ознакомления с представленными документами эксперты решают организационно-технические вопросы, связанные с натурными исследованиями строительного объекта. Для оперативного, всестороннего и полного производства экспертного исследования лицо, назначившее экспертизу, обязано оказывать содействие эксперту в беспрепятственном доступе к объекту и обеспечивать возможность его исследования.

При этом анализ правоприменительной практики свидетельствует о том, что следователи не всегда оказывают необходимое содействие экспертам в процессе организации натурных осмотров строительных объектов, не обеспечивают им беспрепятственный доступ к строительным объектам, а также не помогают при производстве выемки образцов строительных конструкций.

На этапе организации натурного осмотра у эксперта также нередко возникают проблемы, в числе которых, следует отметить следующие:

1. переносится дата и время проведения экспертного осмотра исследуемого строительного объекта, без проведения которого невозможно приступить к проведению исследований;

2. стороны ограничивают доступ к объекту строительно-технической экспертизы для проведения полноценного и качественного экспертного осмотра с проведением необходимых измерений.

Производить осмотр проще, в случае, если эксперту известно какой объект подлежит осмотру, а также о том, наличие (отсутствие) каких объектов предстоит установить, какие их признаки требуется зафиксировать. Кроме того, требуется принять во внимание время суток, погодные условия, освещенность объектов, подлежащих исследованию. 
Для решения обозначенных проблем следователям необходимо взаимодействовать с экспертами на всех этапах производства экспертизы, своевременно представлять им необходимые сведения, а также оказывать содействие и создавать условия для производства всестороннего, полного и объективного экспертного исследования.
Резюмируя вышеизложенное, представляется, что внесенные предложения обладают как теоретической, так и практической значимостью не только для совершенствования процессуального порядка назначения судебной строительно-технической экспертизы, но и для повышения качества тактических приемов и техникокриминалистических средств ее производства.

\section{ЛИТЕРАТУРА}

1. Бутырин А.Ю., Орлов Ю.К. Строительно-техническая экспертиза в современном судопроизводстве: учебник // М.: РФЦСЭ, 2011. 368с.

2. Веренич И.В. Использование специальных знаний в процессе расследования преступлений, совершенных в сфере строительства, эксплуатации зданий и сооружений: Автореф. дис. ... канд. юрид. наук. М., 2010. 27с.

3. Гарькина И.А., Гарькин И.Н. Техническая экспертиза: обоснование демонтажа зданий и сооружений // Фундаментальные исследования. 2017. № 10-3. C. 412-417.

4. Орлов А.К. Проблемы проведения натурных осмотров в рамках уголовного судопроизводства // Судебная строительно-техническая и стоимостная экспертизы: актуальные проблемы и пути их решения: сборник материалов Всероссийской научно-практической конференции в форме «круглого стола» (Москва, 3 октября 2019 г.). М.: Изд-во МИСИ-МГСУ, 2019. С. 96-104. URL: http://mgsu.ru/resources/izdatelskaya-deyatelnost/izdaniya/izdaniya-otkr-dostupa (дата обращения: 13.11.2020).

5. Савенкова Н.С. Совершенствование методов проведения натурного осмотра при производстве строительной судебно-технической экспертизы монолитных железобетонных конструкций // Технология и организация строительного производства. 2017. № 3. С.22-26.

6. Фоменко А.Е. Совершенствование проведения натурных исследований в ходе судебной строительно-технической экспертизы // Теория и практика судебной экспертизы. 2017. № 4 (12). С. 71-77.

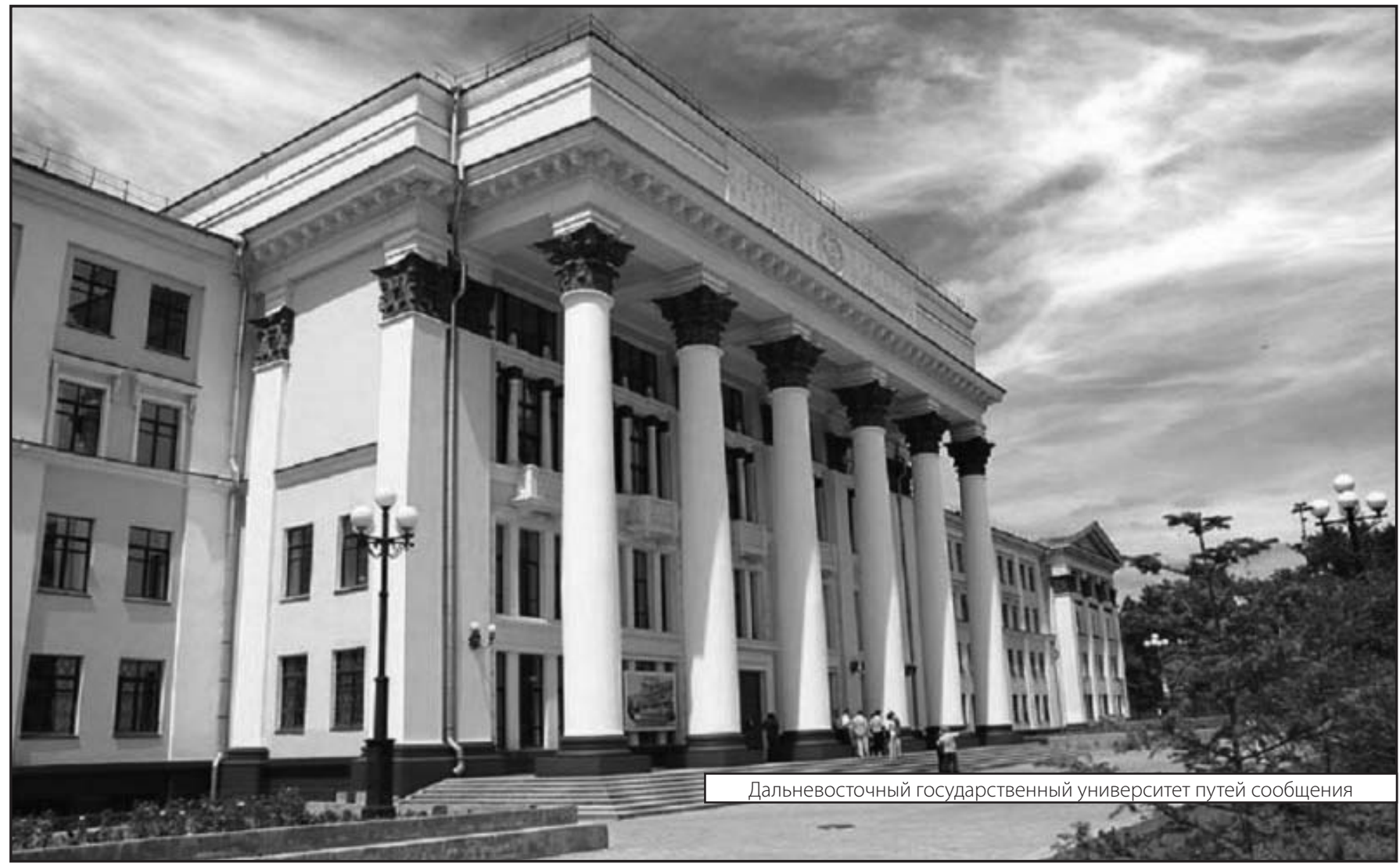

